\title{
Modelling food web interactions, variation in plankton production, and fisheries in the western English Channel ecosystem
}

\author{
Júlio N. Araújo ${ }^{1}$, Steve Mackinson ${ }^{2}$, Richard J. Stanford ${ }^{3}$, David W. Sims ${ }^{4}$, \\ Alan J. Southward ${ }^{4}$, Stephen J. Hawkins ${ }^{4}$, Jim R. Ellis ${ }^{2}$, Paul J. B. Hart ${ }^{1, *}$ \\ ${ }^{1}$ Department of Biology, University of Leicester, Leicester LE1 7RH, UK \\ ${ }^{2}$ CEFAS, Fisheries Laboratory, Pakefield Road, Lowestoft NR33 0HT, UK \\ ${ }^{3}$ Devon Wildlife Trust, 35-37 St David's Hill, Exeter EX4 4DA, UK \\ ${ }^{4}$ Marine Biological Association of the United Kingdom, The Laboratory, Citadel Hill, Plymouth PL1 2PB, UK
}

\begin{abstract}
To explore the contributions that fishing, trophic interactions and plankton production make to explanations of the observed variation of higher trophic (principally fish) levels in the western English Channel ecosystem, Ecosim simulations were run from 1973 to 1999 using the most complete data set yet assembled. The results indicate that a bottom-up mechanism plays an important role in the system production. Inclusion of a primary producer biomass forcing term, estimated from empirical data, improved the goodness of fit of the model estimates to the available biomass data by about $25 \%$ compared to fitting using only the series of fishing mortalities. Model fitting was further improved by changing the so-called vulnerability parameters, causing an overall improvement of $62 \%$ in explained variation. Incorporating the new vulnerability values, the model was used to estimate a primary production anomaly function to replace the primary producer biomass forcing in driving the model simulations. In this scenario, the model estimated a series of values for primary producer abundance that approximated the empirical data, but gave lower estimates than were observed towards the end of the period. This version also gave a better fitting to the zooplankton abundance data and generally improved the fitting to all functional groups.
\end{abstract}

KEY WORDS: Ecopath $\cdot$ Climate change $\cdot$ Ecosystem approach $\cdot$ English Channel

\section{INTRODUCTION}

The western English Channel ecosystem is considered an important biogeographic boundary between northern Boreal and southern Lusitanian fauna and has been subject to many studies regarding the effects of climate change on the abundance of fish and invertebrate species (see Southward et al. 1988, 1995, 2005, Hawkins et al. 2003, Genner et al. 2004). This region has been subjected to major climatic shifts, with mean sea temperature fluctuating with a range of $1.8^{\circ} \mathrm{C}$ over the last century (Southward et al. 2005). Cooler periods of the early 1900s and 1970s were followed by warm- ing periods in the 1950s and from the 1990s to the present day, changes reflected by large-scale patterns in temperatures observed throughout the Northern Hemisphere (Mann 2002). In the last 3 decades in particular, there have been many changes in western English Channel species abundances that appear to be linked to environmental changes. Some of these events are summarized in the following paragraphs.

During the cooling phase of the 1970s and early 1980s many shoals of large mature mackerel Scomber scombrus, instead of overwintering in the northwest coast of the British Isles, migrated to the southwest areas to overwinter and then supported the high 
catches in that region (Lockwood 1988). Also, between 1976 and 1979, the boreal species blue whiting Micromesistius poutassou and Norway pout Trisopterus esmarkii were reported for the first time in the English Channel, coinciding with the great salinity anomaly of the 1970 s, which was caused by a large mass of cool fresher water extending down to $700 \mathrm{~m}$, passing offshore (Cushing 1995). Blue whiting appeared in subsequent surveys of the Marine Biological Association of the UK (MBA), but Norway pout was not reported after 1984 (Southward et al. 2005). The MBA data also shows valuable information on the abundance trends for many other species for which there is no stock assessment data available (Southward et al. 2005). Species such as poor cod Trisopterus minutus, lemon sole Microstomus kitt, grey gurnard Eutrigla gurnardus, dragonet Callionymus lyra, thickback sole Microchirus variegatus and lesser-spotted dogfish Scyliorhinus canicula have shown increasing trends in the MBA data during the last decades, coinciding with the observed warming (Genner et al. 2004, Southward et al. 2005).

The recruitment of the western English Channel plaice Pleuronectes platessa stock increased from the early 1970 s up to 1986 , and after that it started to decrease. This is a very similar pattern to that observed in the eastern English Channel and North Sea, and shows a negative relationship with sea-surface temperature (SST) between February and June (Fox et al. 2000). The International Council for the Exploration of the Sea (ICES) assessment data for the Celtic Sea stock of cod Gadus morhua (ICES divisions VIIe-k), which includes cod in the western English Channel, shows a similar trend in recruitment, increasing from the early 1970s up to 1987, and decreasing afterwards (ICES 2000a). Cod recruitment has been shown to have a negative relationship with the SST in the southern limits of its distribution (Planque \& Fredou 1999). It is believed that in the North Sea a bottom-up control mechanism has reduced cod recruitment, by which the increased temperature since the middle of 1980s has caused changes in the zooplankton community structure and reduced the survival of young cod (Beaugrand et al. 2003).

The recruitment of the western English Channel sole Solea solea stock also increased during the 1970s, but in a different way to the Celtic Sea cod and western English Channel plaice stocks. Sole picked up in 1980, and started decreasing afterwards. The relationship between sole recruitment and temperature does not seem to be so clear as it is for plaice. Rijndsdorp et al. (1992) reported a negative relationship between sole recruitment and winter and early spring temperatures in the North Sea, but this relationship was not observed for the English Channel. In contrast, Hender- son \& Seaby (1994) reported a positive correlation between temperature and sole abundance in Bridgwater Bay, Bristol Channel. Different from the western English Channel plaice and Celtic Sea cod stock, the western English Channel sole stock shows a much stronger relationship between spawning stock biomass and recruitment (ICES 2000a), indicating that mostly density-dependent processes are regulating sole recruitment in the region, while density-independent, environmentally driven mechanisms are the dominant ones for cod and plaice recruitment.

A recent analysis of long-term data collected by the MBA in the western English Channel since the early 1900s (Genner et al. 2004, Southward et al. 2005) showed that despite the increased temperature and fishing, some northern species such as cod have increased in abundance, while large southern species have decreased. It was suggested that food competition release caused by overexploitation of other commercial species and the increase in small non-target prey species have allowed cod to maintain its abundance despite the warming of the last years (Southward et al. 2005). These observations suggest that the response of some species to climate can be counterintuitive and that a complex interaction of factors define the trend in abundance over the years.

The use of ecosystem models provides a framework to identify potential changes that cannot be identified with single-species models, such as counterintuitive changes in abundance when species interactions outweigh the effects of fishing impact or climate change (Fulton \& Smith 2004). The Ecopath with Ecosim (EwE) software (Christensen et al. 2004) is currently the most used and tested ecosystem modelling tool for addressing the issues of how ecosystems are likely to respond to changes in a fishery and the influences of climate at the ecosystem level (Christensen \& Walters 2004, Plagányi \& Butterworth 2004). Fulton \& Smith (2004) compared the results of simulations for Port Phillip Bay, Australia, from EwE with 2 other ecosystem-modelling tools and concluded that they lead to the same general conclusions. In this paper we use a food-web model built using EwE to analyse the contributions that fishing, trophic interactions and plankton production make to explanations of the observed changes in higher trophic levels in the western English Channel from 1973 to 1999 and discuss the results with regard to the influences of the observed climate change. This period was chosen because (1) it includes years when the best information is available; (2) it starts in a relative cold phase and ends in a considerably warmer one; and there was (3) a slight increase in cod and (4) a decrease in the abundance of some of the large southern species despite sea-temperature warming. 


\section{MATERIALS AND METHODS}

Study site. The English Channel is a shallow continental shelf system with a relatively flat bottom. The depth varies from $100 \mathrm{~m}$ in the westernmost part to $40 \mathrm{~m}$ in the Dover Straits. The western English Channel is generally deeper than the eastern part, with the inshore zone more steeply shelving, and much of the Western English Channel is greater than $50 \mathrm{~m}$ in depth. The current system is mainly tidal in nature. There is a gradient related to the vertical mixing in the English Channel during the summer, varying from a thermally stratified system in the west, where there are deeper waters and weaker currents, to relatively better mixed waters in the east, where the system is shallower and stronger currents occur. Between these extremes there is a gradient of transitional conditions, with the occurrence of thermal fronts. The general circulation of water is characterized by a 'river' from the Atlantic to the North Sea and taking 2 routes, one passing through the Celtic Sea and the second through the English Channel (Pawson 1995). The western English Channel accounts for $63 \%$ of the English Channel, covering approximately $56452 \mathrm{~km}^{2}$ (Stanford \& Pitcher 2004) (Fig 1).

Model description and data sources. Christensen et al. (2004) and Christensen \& Walters (2004) gave a detailed description of the EwE software, and critical analyses of the approach can be found in Aydin (2004), Plagányi \& Butterworth (2004) and Fulton \& Smith (2004). The 1973 western English food-web model described in Araújo et al. (2005) was used as a starting point for the simulations presented here. The approach used was first to build a model representing the ecosystem in 1994 using average parameter estimates for 1993 to 1995. This period was selected on the rationale that there were 'high-quality' fisheries data available, which were collected by the Channel Fisheries Study Group (CSFG) (Ulrich et al. 2002). The structure and the basic parameters of the balanced 1994 model were then used as a base-

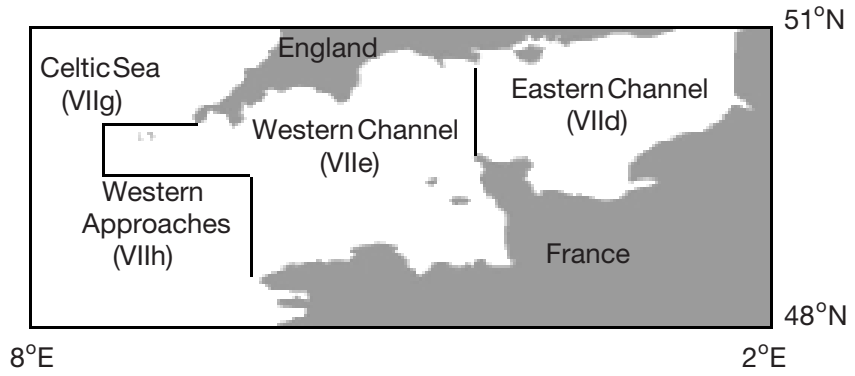

Fig. 1. Western English Channel and adjacent waters. Roman numerals represent ICES areas line upon which to build the 1973 model, and the time series data up to 1999. Fifty functional groups were used to represent the ecosystem. These include 1 primary producer group, 13 invertebrate groups, 32 fish groups, 1 cephalopod group, 1 seabird group and 2 marine mammal groups. Four fish species are represented by 2 functional groups or life stages, juveniles and adults. In addition to the living groups, 2 non-living groups are included to represent detritus and discards. The functional groups and species composition are presented in Appendix 1 (www.intres.com/articles/suppl/m309p175_app.pdf).

The Ecosim simulations run in this work were driven whenever possible by time series of fishing mortalities by functional group. The time-series of biomass, average weight (for split groups) and fishing mortalities $(F)$ and catches $(C)$ were estimated using a combination of data taken from the following sources:

- ICES reports on stock assessment (ICES 1979, 1999, 2000a-c) and the electronic landings database (ICES 2001)

- 'Base Halieutique pour une Manche Stratifiée' (BAHAMAS), an electronic landings database developed by the CFSG (Ulrich et al. 2002)

- MBA long-term trawl data (Genner et al. 2004, Southward et al. 2005)

- RV 'Corystes' beam-trawl surveys of the Centre for Environment, Fisheries and Aquaculture Sciences (CEFAS)

- Continuous Plankton Recorder (CPR) survey data of the Sir Alister Hardy Foundation for Ocean Science (SAHFOS) (Reid et al. 2003)

- Stanford \& Pitcher (2004).

The catch time series of species or functional group was estimated as follows:

$$
C_{\mathrm{e} i}=\frac{C_{\mathrm{I} i}}{C_{\mathrm{I} 1994}} \cdot C_{1994}
$$

where $C_{\mathrm{e} i}$ represents the estimated catches for year $i_{i}$ $C_{\mathrm{I} i}$ and $C_{\mathrm{I} 1994}$ represent the catches available in the ICES database for year $i$ and 1994, respectively, and $C_{1994}$ represents the estimated catches in the 1994 model (based on the BAHAMAS database, when available). This procedure was adopted because there were huge discrepancies between the landings of some species in the BAHAMAS database (Ulrich et al. 2002, Stanford \& Pitcher 2004) and the ICES database for 1993 to 1995. The rationale to adopt this procedure was that the data in the BAHAMAS database is considered the best information available and there was no accurate information for the other years of the series (Stanford \& Pitcher 2004).

The biomass time series for the species for which there are virtual population analysis (VPA) estimates available were estimated as: 


$$
B_{\mathrm{e} i}=\frac{B_{\mathrm{I} i}}{B_{\mathrm{I} 1994}} \cdot B_{1994}
$$

where $B_{\mathrm{e} i}$ represents the estimated biomass for year $i_{i}$ $B_{\mathrm{I} i}$ and $B_{\mathrm{I} 1994}$ represent the biomass estimates in the ICES reports for year $i$ and 1994 respectively; and $B_{1994}$ represents the estimated biomass in the 1994 balanced model. This method was used to provide time series of biomass estimates for the stocks for which the assessment data include other ICES divisions besides the western English Channel (division VIIe). For example whiting Merlangius merlangus in the western English Channel is managed as part of the Celtic Sea stock (VIIe-k) (ICES 2000a), and by using Eq. (2), we assumed that the abundance of the species in the western English Channel followed the same trend of the whole stock.

The MBA catch $(\log ($ number +1$))$ per unit of effort (CPUE) data was used as a index of abundance to roughly estimate the biomass variation for some fish groups that do not have biomass estimates derived from VPA and to complement VPA series for some species that did not cover the whole period. The MBA data used was split into 3 groups. The 1968-1979 average was used to represent the relative abundance in the 1973 model; the 1983-1986 average was for 1985 . As there was no MBA surveys data for the 1990s, we used the 2000-2001 average and in some cases the 1983- 2001 average as a surrogate for the 1994 model relative abundance index. For species where there was no abundance estimate available, the ratio between the abundances in the 1973 and 1994 models was based on best guesses (see Araujo et al. 2005). After the reference years' biomasses had been estimated, a linear trend was calculated to fill in the years between them and to allow the time series of fishing mortality to be estimated. Although we estimated biomass values for all years in the series to allow the estimation of fishing mortalities, when the estimates were based on the MBA data or on best guesses, only the reference years were used to fit the model. We did this to give less weight to the estimate data in the fitting procedure. The fishing mortality series were then estimated as $C / B$ as that is the way it is computed in the Ecopath software.

Time series data of the average annual phytoplankton colour index and the average annual zooplankton abundance for the western English Channel were available from the CPR program. A 3 yr running mean was estimated to smooth the trend. The zooplankton data were used to estimate a biomass time series for the mesozooplankton, since we assumed that the main species in the data set (general group 'small copepods', $<2 \mathrm{~mm}$ ) are mostly representative of this functional group. The phytoplankton data trend was used to esti- mate a biomass forcing function to drive the primary producers group in the Ecosim simulations (see below). The available biomass time series for all other groups were entered in the fitting procedure as absolute values, except zooplankton, for which the series was entered as relative values, which resulted in a lower weight for this group in the fitting procedure.

Values of annual biomass accumulation rates $(-0.05$ or +0.05 ) were included in most model groups for which the simulations were driven by time series of fishing mortality. The value was set according to the biomass trend in the years following 1973. Additional information and comments on the time series estimation procedure and the adjustments that were made on the base line parameters of the 1973 model are presented in Appendix 2 (www.int-res.com/articles/suppl/ m309p175_app.pdf).

Ecosim simulations. The consumption $(Q)$ of a predator in the Ecosim simulations varies as a function of its biomass and the biomass of its prey and a parameter called 'vulnerability' $(v)$ that conceptually represents a theoretical flow rate at which the prey biomass moves from a vulnerable state to an invulnerable one. As implemented, the vulnerability is the maximum mortality that a predator can cause on a given prey, relative to the Ecopath base mortality rate, if the predator numbers were to be very high. It is estimated as $v_{i j}=v_{i j}^{\prime} Q_{i j} / B_{i i}$, where $Q_{i j}$ is the Ecopath baseline estimate of the consumption of species $i$ by species $j$ and $B_{i}$ is the biomass of $i$. The parameter $v^{\prime}{ }_{i j}$, which determines the maximum $Q_{i j}$ is usually called vulnerability as well. This is an input in Ecosim and can vary from 1 (bottom-up) to $\infty$ (top-down control), its default value being 2 . The simulations have been shown to be very sensitive to changes in the vulnerability parameter $\left(V_{i j}^{\prime}\right)$ : low values cause bottom-up control, whereas high values result in top-down Lotka-Volterra predator-prey dynamics, with extreme cases leading to dynamic instability (predator-prey cycles) and loss of biodiversity through the overexploitation of some functional groups by their predators. Although users can input values of $v_{i j}^{\prime}$ into Ecosim, it is not advisable to do so other than for the purposes of testing or comparing the dynamics of models, since there is little way of knowing (or measuring in the field) what these values could or should be. However, recent interpretations suggest that knowing how abundant the species is relative to its virgin abundance can provide guidance on whether the vulnerability parameter should be high or low (Plagányi \& Butterworth 2004, V. Christensen pers. comm.). Where a predator's abundance is far below its carrying capacity, high vulnerabilities of its prey mean that the predator is capable of inflicting higher mortality, increasing its consumption and thus recovering more quickly. It is now advised to estimate 
the vulnerabilities by fitting the model estimates (e.g. biomass) to observed time series data (Walters et al. 2000, Christensen et al. 2004, Plagányi \& Butterworth 2004, Walters \& Martel 2004).

To analyse the relative roles of fishing, trophic interactions and system productivity to account for the observed changes in biomass of different functional groups, we followed a similar procedure to that described by Shannon et al. (2004). Basically, we assessed the effects of fishing mortality, primary production changes and vulnerability parameters by using the following steps.

(1) The Ecosim simulation was run from 1973 to 1999, applying constant fishing mortalities $(F)$, i.e. using the 1973 model baseline estimates. Ecosim calculated a sum of squared deviations (SS) of log observed biomass from log predicted biomass, which was recorded so that it could be compared to the SS estimated in subsequent steps. Therefore, a reduction in the SS represented an improvement in the model estimates.

(2) The model was run with time-varying fishing mortalities.

(3) The model was run with constant fishing mortalities and including the primary production biomass forcing $(\mathrm{PBF})$.

(4) The model was run with time-varying fishing mortalities and including the PBF.

(5) Using the settings of Step 4, the Ecosim non-linear tool was used to estimate the vulnerability parameters. To assess the effects of different starting values for the vulnerabilities, we ran the non-linear search tool 8 times, starting with the default value 2 , and then trying 1.5, 3, 4 and so on up to 8 to estimate the average vulnerability of the prey to each predator, i.e. assuming that the vulnerabilities to a particular predator have the same value.

(6) The biomass forcing was replaced by a primary production anomaly function (PAF) estimated by the non-linear tool to 'drive' the production of the primary producers group. The PAF was estimated using the vulnerability settings estimated in Step 5.

(7) Alternatively to Steps 4 to 6, the Ecosim non-linear tool was used to estimate the vulnerability parameters without the inclusion of the PBF.

(8) The Ecosim non-linear tool was used to estimate a PAF.

\section{RESULTS}

Surprisingly, the inclusion of a time series of $F$ (Step 2) did not reduce the SS when compared to Step 1 (Table 1). The use of the PBF with constant F (Step 3) gave a better fitting than in Step 2, but worse than in Step 1 . When the model was run with time series of $F$ and the PBF (Step 4), it resulted in a better fitting than in Step 1. This version of the model was then used to
Table 1. Ecosim runs with the respective sum of squared deviations (SS) of log biomass from log predicted biomass. $F=$ fishing mortality; $\mathrm{PBF}=$ primary producers biomass forcing; $\mathrm{PAF}=$ primary producers anomaly function $; v=$ vulnerabilities

\begin{tabular}{|llc|}
\hline Step & Settings & SS \\
\hline 1 & Constant $F$ & 70.92 \\
2 & Time-varying $F$ & 84.84 \\
3 & Constant $F+$ PBF & 81.63 \\
4 & Time-varying $F+$ PBF & 63.68 \\
5 a & Time-varying $F+$ PBF $v$ & 29.66 \\
$5 b$ & As above but with an upper limit of 10 to $V$ & 32.19 \\
6 & Time-varying $F+V$ (from 5b) PAF & 26.32 \\
7 & Time-varying $F V$ & 28.94 \\
8 & Time-varying $F+V$ (from 7$)$ PAF & 26.79 \\
\hline
\end{tabular}

estimate the vulnerabilities by further reducing the SS with the aid of the non-linear search tool (Step 5).

The final SS for each of the 8 runs of the non-linear search tool using different starting values were similar, probably because the vulnerabilities of the prey of some predators in these different runs were fairly constant. For example, the vulnerabilities of the prey of juvenile sole varied from 2.3 to 3.1 . On the other hand, some groups (mainly the groups that do not have any abundance 'driver', i.e., fishing mortality) presented huge variations in the estimated vulnerabilities of their prey (Appendix 3; www.int-res.com/articles/ suppl/m309p175_app.pdf). It shows that very different combinations for the vulnerabilities of the prey of some groups can result in fairly similar fittings.

We used the estimates from the run that started with the default settings and which gave the best fitting (Step 5a in Table 1) to set an upper limit of 10 to the vulnerabilities, since higher values did not improve the fitting significantly and because the model was very unstable with these vulnerability settings when run in a no fishing scenario. The final SS was higher after these manipulations (Step 5b in Table 1), but with these vulnerability settings the model presented a much more 'stable behaviour' when run in a scenario with no fishing (results not shown). The final (capped) vulnerability settings are shown in the Appendix 3. The results show that the preys of most demersal fish groups tended to have higher vulnerabilities than the preys of the pelagic ones.

In the Step 6, the model was run without the PBF and the non-linear search tool was used to estimate the PAF. This further improved the model fitting, and the PAF showed a similar trend to the PBFs (see Fig. 2).

Finally, the SS estimated in Step 7 shows that it was possible to improve significantly the fitting just by changing the vulnerabilities. The vulnerability for the prey of most groups estimated in this step were relatively similar to the ones of Step $5 \mathrm{a}$, but for the prey of 

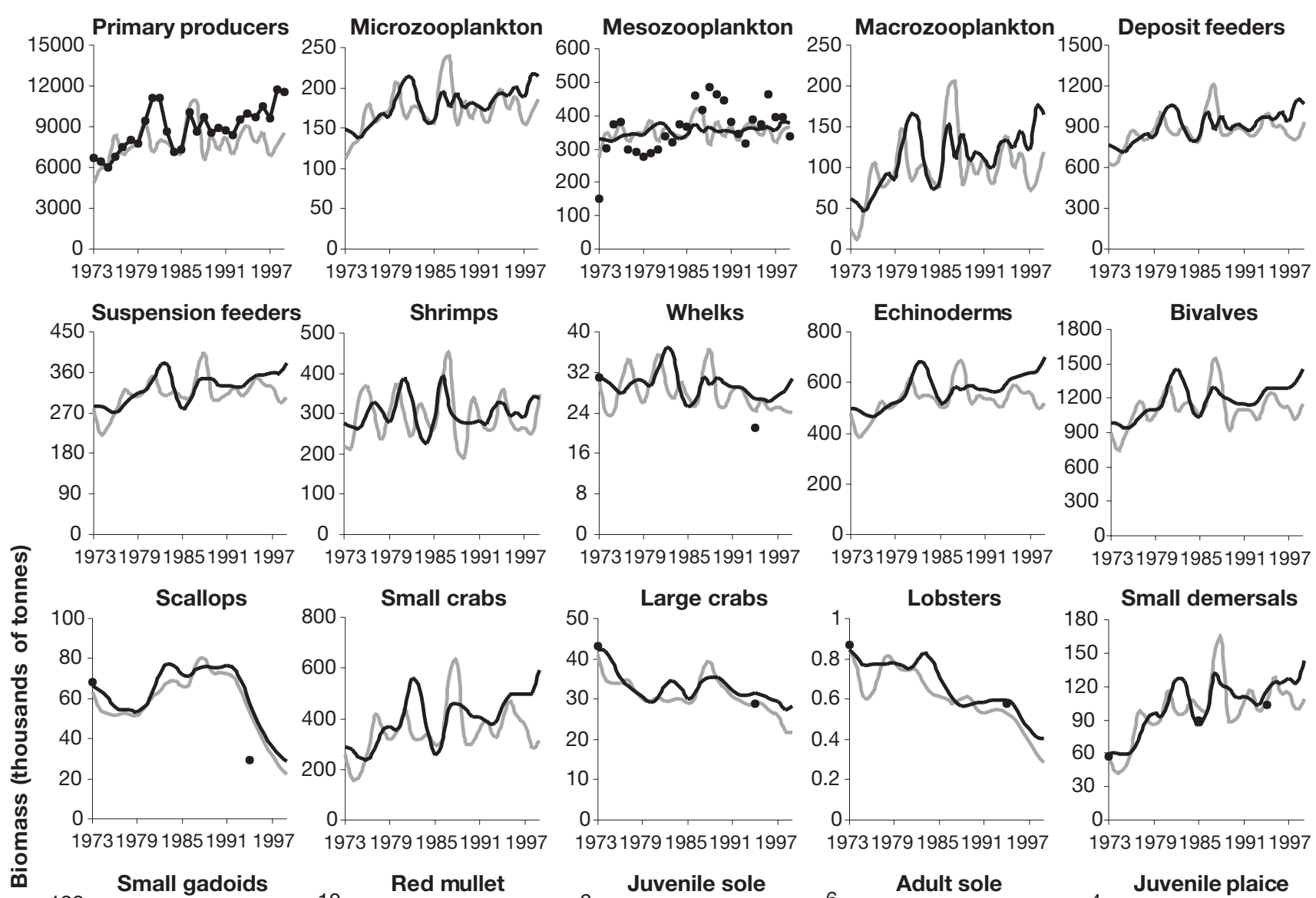

19731979198519911997
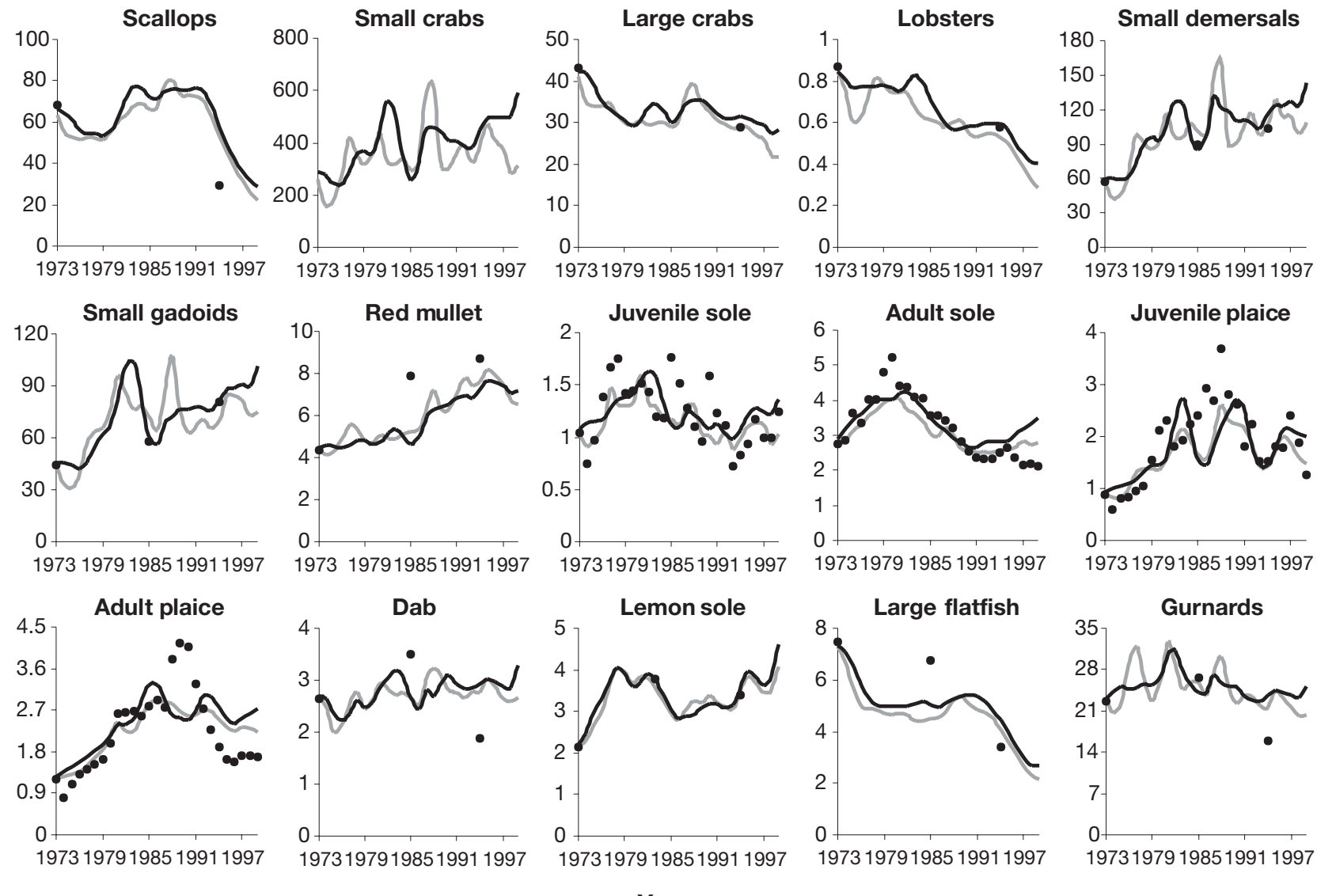

Years

Fig. 2. Biomass time series estimates for the western English Channel ecosystem from 1973 to 1999. Dots represent the input estimates; black lines represent Ecosim estimates using a scenario with primary producer biomass forcing (PBF); grey lines are for the scenario using a primary producer anomaly function (PAF)

13 groups they differed by at least 1 order of magnitude. The PAF estimated in Step 8 using the vulnerability settings from Step 7 did not approximate the PBF (results not shown). It implies that very different mechanism could well explain the observed variation in the biomass series. 

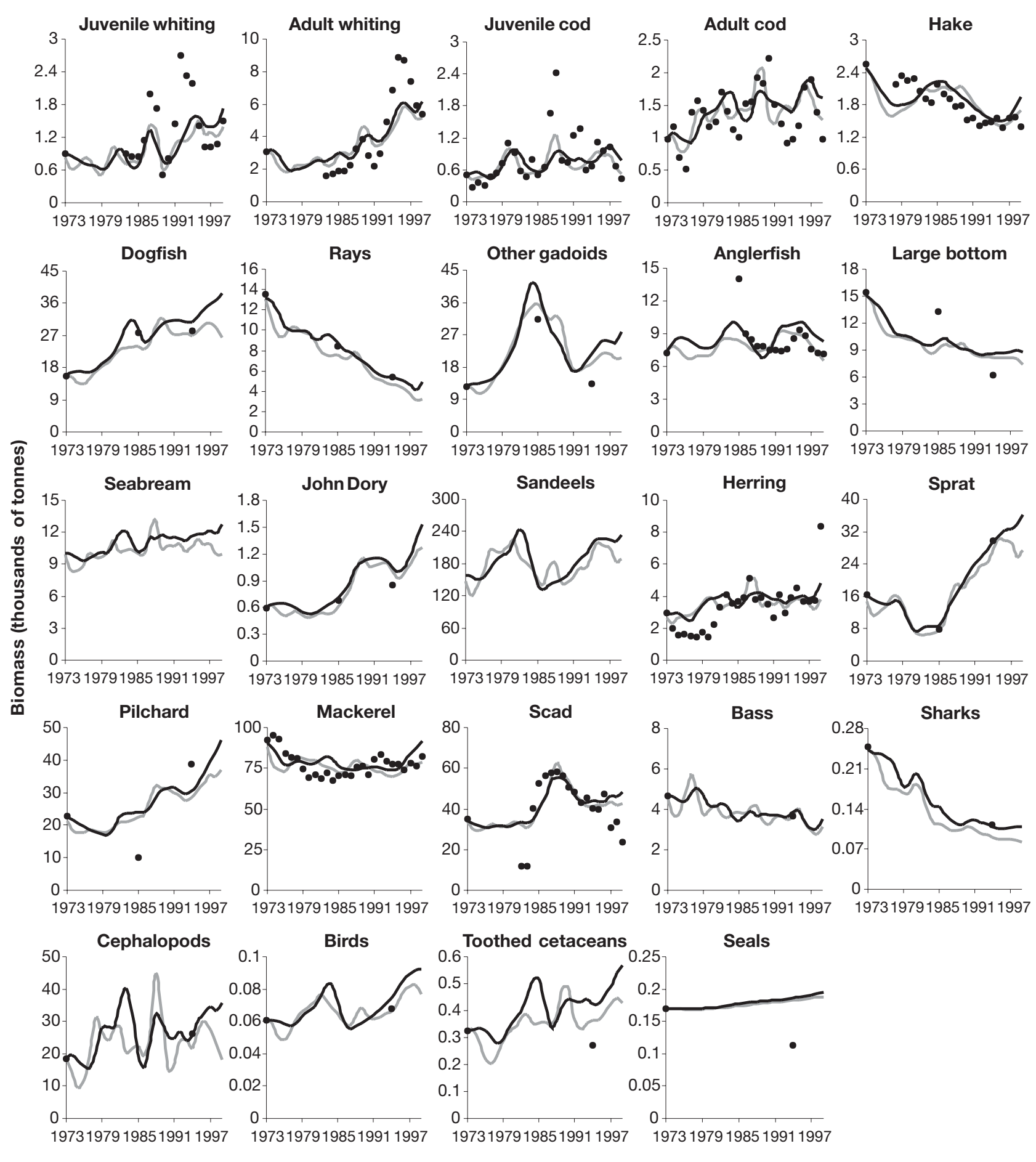

\section{Years}

Fig. 2 (continued)

The results of model simulations of Steps 5 and 6 for both biomass and catch are shown in Figs. 2 \& 3, respectively. The time series data of the average annual phytoplankton colour index that was used to estimate the PBF shows an increasing trend from 1973 to 1999 (Fig. 2). The trend was not constant, showing oscillations throughout the period. Two main peaks are evident in the early 1980s and in the late 1990s, with an additional but smaller peak in the late 1980s. Similarly, the zooplankton time series data shows a general 


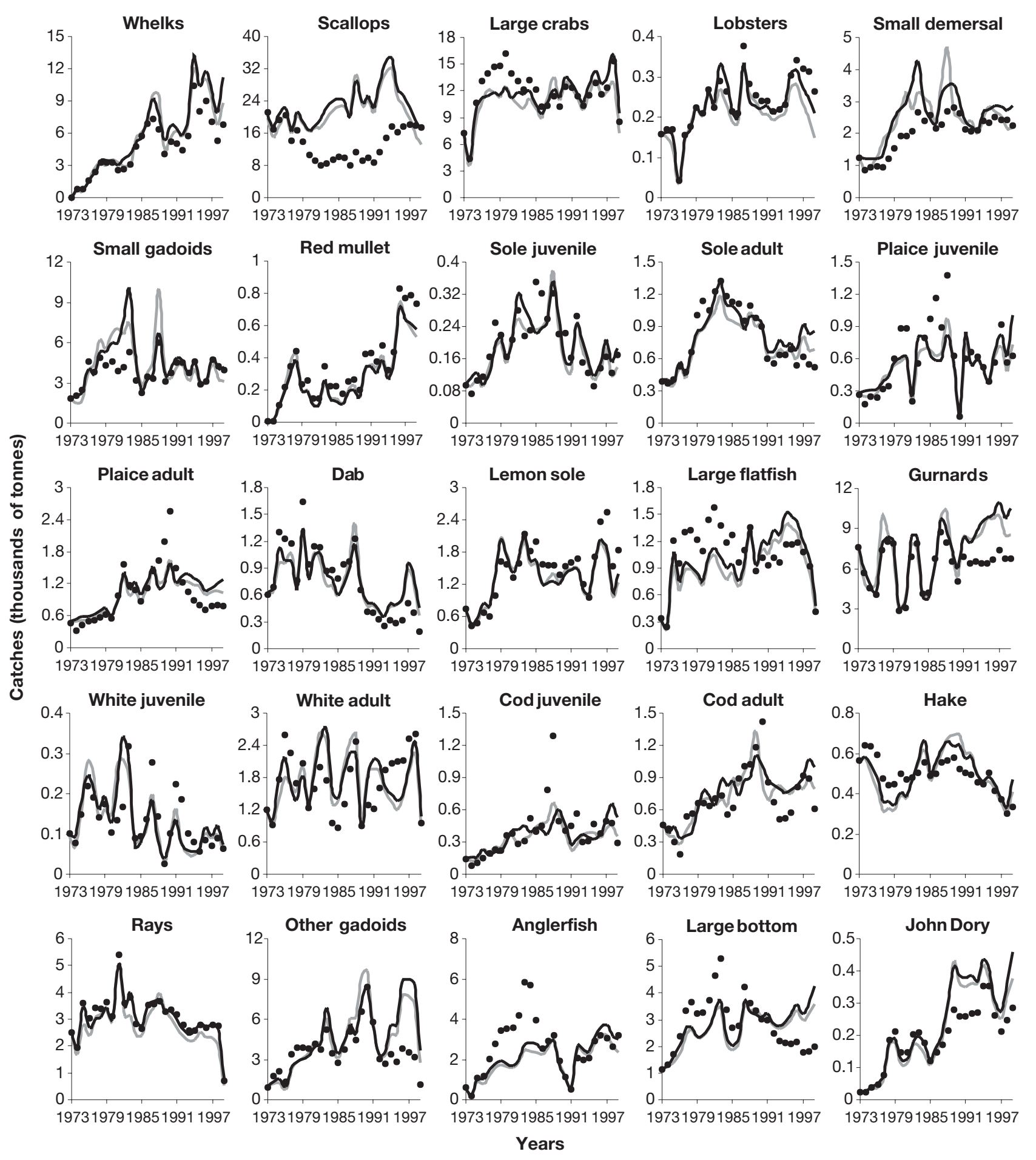

Fig. 3. Catch time series estimates for the western English Channel ecosystem from 1973 to 1999. Dots represent the input estimates; black lines represent Ecosim estimates using a scenario with primary producer biomass forcing (PBF); grey lines are for the scenario using a primary producer anomaly function (PAF)

increasing trend from 1973 to 1999, but a period of higher production is observed in the second half of the 1980s, coinciding with a smaller peak in the phytoplankton. Although the observed zooplankton abun- dance was much higher at the end than at the start of the series, a decreasing trend was shown over the last few years, contrary to the trend shown by the phytoplankton series. 


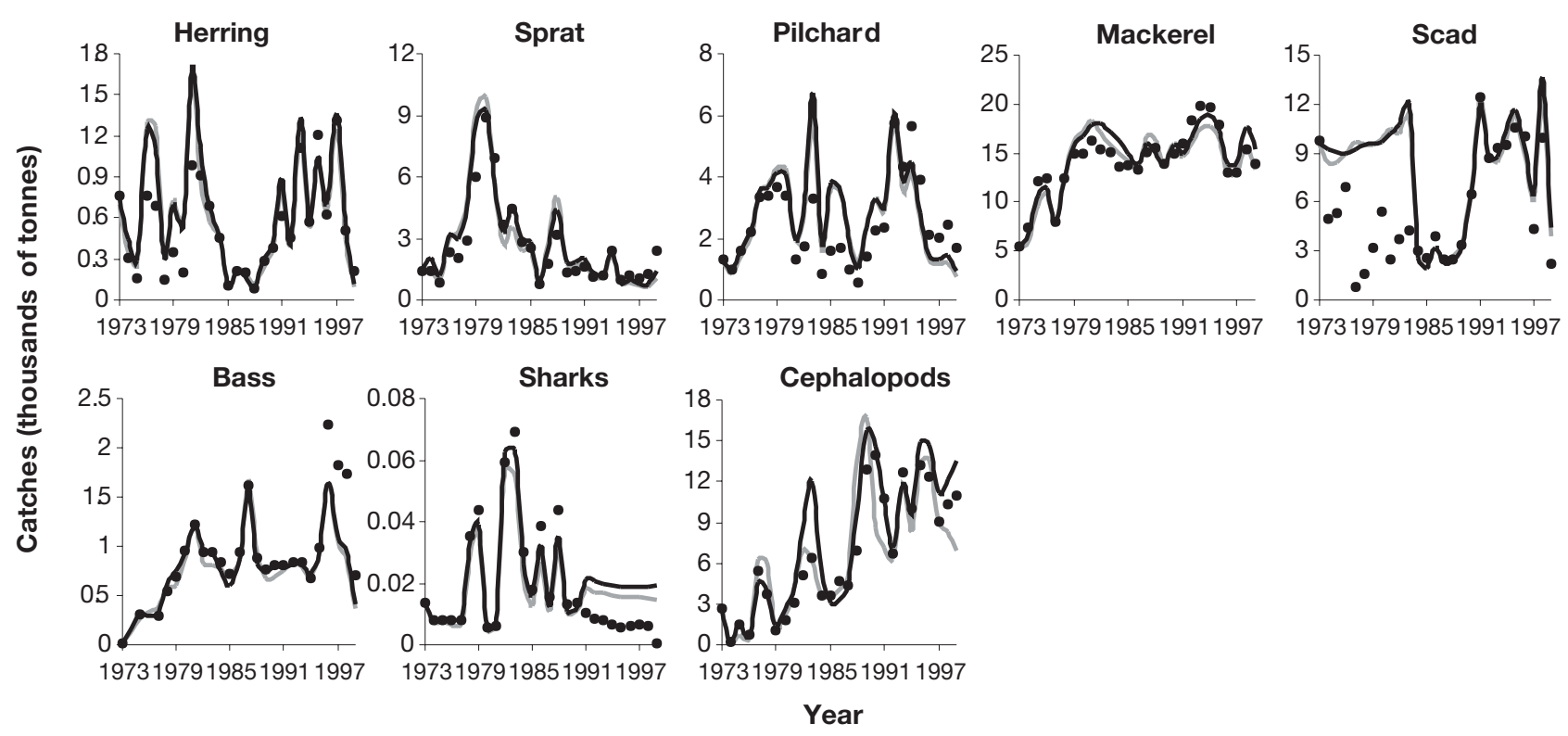

Fig. 3. (continued)

Many of the fish groups increased during these years, presenting a trend similar to the zooplankton production, with production peaking sometime during the 1980s and decreasing afterwards. For example, for sole, plaice and cod, species for which there are time series of fishing mortalities derived from VPA, it is worth noting that, even though $F$ slightly increased, their biomass also increased for some time during the first few years of the series. These observations suggest factors other than just fishing could be contributing to observed abundance changes for these commercial species. So, the improvement in the fit to the time series that resulted from including the PBF shows that a bottom-up mechanism contributes to the production of high trophic levels.
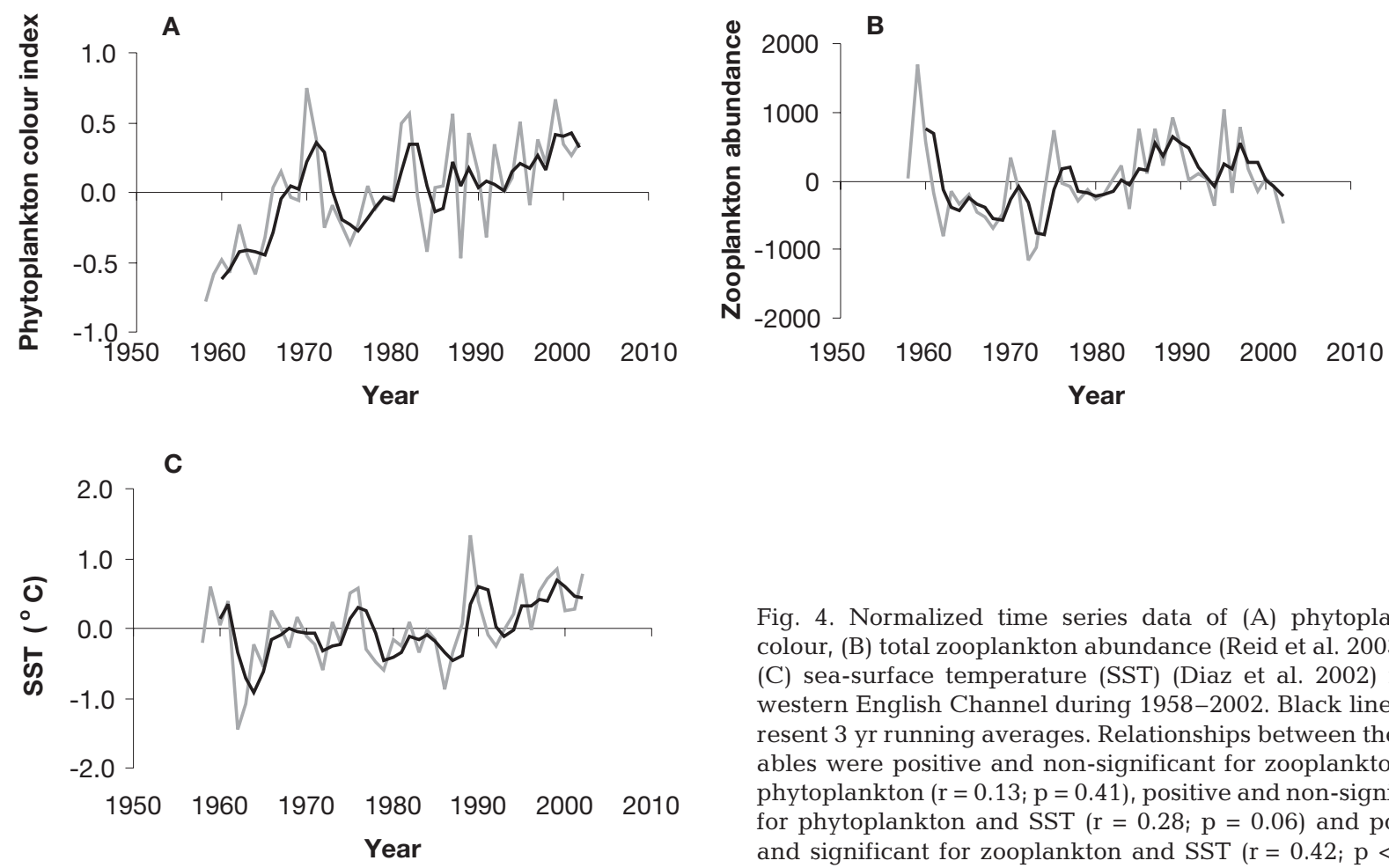

Fig. 4. Normalized time series data of (A) phytoplankton colour, (B) total zooplankton abundance (Reid et al. 2003) and (C) sea-surface temperature (SST) (Diaz et al. 2002) in the western English Channel during 1958-2002. Black lines represent 3 yr running averages. Relationships between the variables were positive and non-significant for zooplankton and phytoplankton $(r=0.13 ; p=0.41)$, positive and non-significant for phytoplankton and SST $(\mathrm{r}=0.28 ; \mathrm{p}=0.06)$ and positive and significant for zooplankton and SST $(\mathrm{r}=0.42 ; \mathrm{p}<0.01)$ 
Although the inclusion of the PBF improved the overall fit of the model to the biomass time series, the model generally overestimated the biomass and yield towards the end of the period. The replacement of the PBF by PAF improved the fitting somewhat. The primary production series in the PAF scenario roughly resembled the PBF $\left(r^{2}=0.194, p<0.05\right)$, but with lower estimates and almost no trend towards the end of the period. This shows that increased primary production observed at the end of the series was not being converted into increased production for many higher trophic levels, including zooplankton, where the data from the CPR show a decreasing trend in the same period. The inclusion of the PAF also considerably improved the abundance estimates for the mesozooplankton group compared with the estimates of the PBF scenario, although the estimates show a much lower variability than the observed data $\left(r^{2}=0.188, p=\right.$ 0.05). The model also predicted a general increase in benthic, non-commercial species groups, using both PBF and PAF scenarios. The estimated trend for these groups roughly resembled the trend in the primary producers for each scenario.

\section{DISCUSSION}

The inclusion of the PBF improved the fit of the model biomass estimates to the biomass time series. As for many high trophic level groups, phytoplankton and zooplankton data show an increasing trend from 1973. However, in a different manner from the higher trophic levels, the phytoplankton data show that the production kept on increasing up to the end of the time period. On the other hand, many fish groups increased up to the 1980s, after which they started decreasing. The zooplankton data show a similar trend to the fish groups, with the period of highest production occurring in the late 1980s, and a decreasing trend afterwards. The CPR average zooplankton abundance in the western English Channel is positively related to the phytoplankton index and the annual SST, although only the relationship between zooplankton and SST is significant (Fig. 4). The fact that zooplankton slightly decreased towards the end period while phytoplankton kept on increasing and the fact that zooplankton seems to have a stronger relationship with SST than with phytoplankton suggest that the overall zooplankton abundance does not seem to be tightly linked to the primary production in the western English Channel. This is despite the suggestion by Richardson \& Schoeman (2004) that there is a tight bottom-up control of zooplankton from phytoplankton for the Northeast Atlantic, with the SST being the underlying driving force. In addition, Edwards et al. (2001) observed that in the North Sea the increased phytoplankton production associated with higher temperatures could be associated with a shift in the phytoplankton community composition favouring 'unpalatable and noxious species' with important ramifications through the various marine trophic levels.

After the vulnerabilities were estimated, the model estimated a PAF that had a trend similar to the PBF, but with lower estimates for the later years. If these results are not just a model artefact, they may be seen as evidence that the production of many of the higher trophic levels is not tightly linked to primary production. These discrepancies might be related to the fact that zooplankton production itself is not a simple function of primary production, but also related to physical processes, as discussed earlier, and these processes are not modelled in Ecosim. Alternatively, the primary producers biomass may not have increased very much. We used the CPR phytoplankton colour index and assumed that the index is directly proportional to changes in biomass, but the relationship between the variation of this index and the variation in the phytoplankton biomass is presently not well understood (Edwards et al. 2001, Barton et al. 2003).

It can be argued that some species might respond very differently to environmental changes and that the use of one single mechanism to explain the overall production of the ecosystem would be misleading. A complicating factor when using an ecosystem modelling approach for the western English Channel derives from the observation that this ecosystem is a biogeographic boundary between the northern Boreal and the southern Lusitanian fauna. The abundance of important species will be not only a function of primary and secondary production, but also related to distributions as a function of temperature. The change in the mackerel overwintering behaviour during the 1970s (Lockwood 1988) is a remarkable and perhaps extreme example. Also, physical processes along with food abundance and predation mortality might regulate the survivorship in the early life stages. For example, Bradbury et al. (2001), using a model of temperaturedependent cod-egg development and mortality in Placentia Bay, Newfoundland, suggested that the effects of predation are small relative to the effects of advection, and that the interaction between advection and temperature-dependent vital rates for eggs may have dramatic consequences for the coastal retention of eggs. The mechanisms regulating the production of early stages will also differ among different species in the same ecosystem. Koster et al. (2003) observed that for cod in the Baltic Sea the period between the late egg and early larval stages is critical for recruitment and that the potential factor affecting this stage was the prey availability for larvae. On the other hand, the 
period between the late larval and early juvenile stages seemed to be important for sprat recruitment. The potential causes affecting this life stage were ambient temperature and wind stress. In the North Sea, survival of young cod would be indirectly and negatively linked to temperature through changes in the zooplankton community structure, i.e., food availability (Beaugrand et al. 2003). In such a case, the increased production of some zooplankton species, not the overall production, would affect recruitment. However the situation of the cod stock in the ICES divisions VIIe-k, which includes the western English Channel, seems to be different. Despite the warming, the stock produced relatively good year-classes in 1999 and 2000, and the spawning stock biomass has increased slightly since then (ICES 2005), suggesting the occurrence of somewhat different mechanisms regulating the abundance of cod in this ecosystem.

Walters \& Martell (2004) reported that the inclusion of a primary production anomaly helped to improve the Ecosim fittings and explained the positive covariation in abundances of different species in the West Coast Vancouver Island and Georgia Strait ecosystems. On the other hand, including such a function did not improve the fit of models for the central North Pacific, Gulf of Thailand and the North Sea. Shannon et al. (2004) were able to explain 4 to $12 \%$ of the variance in the time series data for the southern Benguela ecosystem by estimating a primary production anomaly. Cury et al. (2003) affirmed that bottom-up control seems to affect most ecosystems, and Ware \& Thomson (2005) showed that primary production variation is highly correlated with the resident fish yield along the northeast Pacific continental margin between 34.3 and $58.5^{\circ} \mathrm{N}$. So, there is some evidence from other ecosystems to support the main observation presented here that a bottom-up mechanism has a relatively strong effect across different trophic levels in the western English Channel ecosystem. In addition, Walters \& Martell (2004) state that strong top-down control by predators appears to be relatively uncommon in marine ecosystems. In this case, predation and/or food competition release caused by removal by fishing of selected top predators would have less importance than environmentally driven changes in productivity of lower trophic levels.

In some previous work with Ecosim modelling (eg. Harvey et al. 2003, Shannon et al. 2004), the authors have interpreted the vulnerability values estimated during the time series fitting as reflecting mechanisms of bottom-up versus top-down prey-predator dynamics. However, the vulnerabilities rather explain where group abundances are placed relative to their carrying capacities (Plagányi \& Butterworth 2004, V. Christensen pers. comm.). Hence, in the case of the present study, we observed that the prey of many demersal predators tends to have high vulnerabilities, so indicating that the predators are not close to their carrying capacity. This might be because they have been reduced from their original abundance or because of better food conditions. Although we have shown here that it is quite possible to achieve fairly similar fittings with very different combinations of vulnerability parameters for the prey items of some groups, implying that some very different mechanism could well explain the observed variation, the incorporation of a known process, such as the observed primary production variation, in the model formulation to estimate the vulnerabilities seems to give more credibility to our results. It is clear that considering the level of uncertainty of some time series inputs used to fit the model estimates, and the fact that Araújo et al. (2005) used the 1990s model diet matrix as first guess for the 1970s diets, the estimates of the vulnerabilities should be interpreted with caution. Furthermore, Aydin (2004) states that successful fitting of models does not guarantee a mechanistic explanation of the observed abundance variation, and as stated by Christensen et al. (2004, p. 112), many model errors can result from omissions of otherwise unknown predator-prey interactions and forcing functions representing environmental processes. According to Christensen et al. (2004), 'such possible omissions are most productively viewed as alternative hypotheses about what processes and inputs have been important in shaping historical ecosystem behaviour.'

We have explored in this paper how fishing, trophic interactions and plankton production contribute to the observed variation of high trophic levels. By accounting for the phytoplankton variation observed in the CPR data, we were able to improve the goodness of fit of the model estimates to the available biomass data by about $25 \%$ compared with fitting the model by using only the series of fishing mortalities. The model fitting was further improved by changing the vulnerability settings and thus caused an overall improvement of $62 \%$ in explained variation. These results show that, in addition to fishing, a bottom-up environmentally driven mechanism plays an important role in the system production, but complex trophic flows should be also considered for an explanation of the observed variation.

In recent years, many papers dealing with the influence of climate change on phytoplankton and zooplankton have been published. Some of these papers have dealt with time series data covering more than $40 \mathrm{yr}$, and the findings suggest that there is a link between plankton production and climate, although such a period can be viewed as short when analysing multi-decadal variability (Barton et al. 2003). Barton et 
al. (2003) proposed that between 1970 and 2000 anomalously warm SST and high nutrient availability related to an increasing trend in the North Atlantic Oscillation index led to a increased phytoplankton production in some Northeast Atlantic shelf ecosystems, including waters adjacent to the British Isles. Richardson \& Schoeman (2004) provided evidence that there is a certain degree of bottom-up control of zooplankton abundance by phytoplankton over a period of 4 decades for the Northeast Atlantic. It is reasonable to suppose that these persistent changes will propagate through the food web and affect the production at higher trophic levels, although, as stated by Genner et al. (2004), additional local environmental determinants, interspecific interactions and dispersal capacity, and we also include here differences in fishing pressure, will affect regional responses of different species and populations of the same species to changes in climate.

Acknowledgements. The authors thank Christian Dintheer of the French Research Institute for Exploitation of the Sea and the Sir Alister Hardy Foundation for giving access to the BAHAMAS and CPR databases respectively. This work was partially funded through a $\mathrm{PhD}$ grant to J.N.A. given by CAPES - Coordenação de Aperfeiçoamento de Pessoal de Nível Superior - agency of the Brazilian Ministry of Culture and Education. MBA trawl surveys were re-started in 2000 with support provided by the UK Department for Environment, Food and Rural Affairs, and the Natural Environment Research Council. D.W.S. and S.J.H. are supported by NERCfunded MBA Research Fellowships.

\section{LITERATURE CITED}

Araújo JN, Mackinson S, Ellis JR, Hart PJB (2005) An Ecopath model of the western English Channel ecosystem with an exploration of its dynamic properties. Science Series Technical Reports 125. Centre for Environment, Fisheries and Aquaculture Science, Lowestoft

Aydin KY (2004) Age structure or functional response? Reconciling the energetics of surplus production between singlespecies models and ECOSIM. Afr J Mar Sci 26:289-301

Barton AD, Greene CH, Monger BC, Pershing AJ (2003) The Continuous Plankton Recorder survey and the North Atlantic Oscillation: interannual- to multidecadal-scale patterns of phytoplankton variability in the North Atlantic Ocean. Prog Oceanogr 58:337-358

Beaugrand G, Brander KM, Lindley JA, Souissi S, Reid PC (2003) Plankton effect on cod recruitment in the North Sea. Nature 426:661-664

Bradbury IR, Snelgrove PVR, Fraser S (2001) The influence of temperature on advective loss of Atlantic cod (Gadus morhua) eggs from the inshore environment. Fish Oceanogr 10:342-352

Christensen V, Walters C (2004) Ecopath with Ecosim: methods, capabilities and limitations. Ecol Model 172:109-139

Christensen V, Walters C, Pauly D (2004) Ecopath with Ecosim: a user's guide. Fisheries Centre Research Reports, Vol 12(4). University of British Columbia, Vancouver

Cury P, Shannon L, Shin YJ (2003) The functioning of marine ecosystems: a fisheries perspective. In: Sinclair M, Valdi- marsson G (eds) Responsible fisheries in the marine ecosystem. CAB International, Wallingford, p 103-123

Cushing DH (1995) Population production and regulation in the sea: a fisheries perspective. Cambridge University Press, Cambridge

Diaz H, Folland C Manabe T, Parker D Reynolds R, Woodruff S (2002) Workshop on advances in the use of historical marine climate data. WMO Bull 51:377-380

Edwards M, Reid P, Planque B (2001) Long-term and regional variability of phytoplankton biomass in the Northeast Atlantic (1960-1995). ICES J Mar Sci 58:39-49

Fox CJ, Planque BP, Darby CD (2000) Synchrony in the recruitment time-series of plaice (Pleuronectes platessa L.) around the United Kingdom and the influence of sea temperature. J Sea Res 44:159-168

Fulton EA, Smith ADM (2004) Lessons learnt from a comparison of three ecosystem models for Port Phillip Bay, Australia. Afr J Mar Sci 26:219-243

Genner MJ, Sims DW, Wearmouth VJ, Southall EJ, Southward AJ, Henderson PA, Hawkins SJ (2004) Regional climatic warming drives long-term community changes of British marine fish. Proc R Soc B 271:655-661

Harvey CJ, Cox SP, Essington TE, Hansson S, Kitchell JF (2003) An ecosystem model of food web and fisheries interactions in the Baltic Sea. ICES J Mar Sci 60:939-950

Hawkins SJ, Southward AJ, Genner MJ (2003) Detection of environmental change in a marine ecosystem - evidence from the western English Channel. Sci Total Environ 310: $245-256$

Henderson PA, Seaby RMH (1994) On the factors influencing juvenile flatfish abundance in the lower Severn Estuary, England. Neth J Sea Res 32:321-330

ICES (1979) Report of the Homarus working group. International Council for the Exploration of the Sea, Copenhagen

ICES (1999) Report of the working group on the assessment of mackerel, horse mackerel, sardine and anchovy. International Council for the Exploration of the Sea, Copenhagen

ICES (2000a) Report of the working group on the assessment of southern shelf demersal stocks. International Council for the Exploration of the Sea, Copenhagen

ICES (2000b) Report of the working group on the assessment of demersal stocks in the North Sea and Skagerrak. International Council for the Exploration of the Sea, Copenhagen

ICES (2000c) Report of the herring assessment working group for the area south of $62 \mathrm{~N}$, Part 1. International Council for the Exploration of the Sea, Copenhagen

ICES (2001) ICES fisheries statistics, catch data 1973-2000. CD-ROM: database in FishStatPlus. International Council for the Exploration of the Sea, Copenhagen

ICES (2005) Report of the working group on the assessment of demersal stocks in the North Sea and Skagerrak. International Council for the Exploration of the Sea, Copenhagen

Koster FW, Hinrichsen HH, Schnack D, St John MA, Mackenzie BR and 6 others (2003) Recruitment of Baltic cod and sprat stocks: identification of critical life stages and incorporation of environmental variability into stock-recruitment relationships. Sci Mar 67:129-154

Lockwood SJ (1988) The mackerel: its biology, assessment and the management of a fishery. Fishing News Books Farnham

Mann ME (2002) Climate reconstruction: the value of multiple proxies. Science 297:1481-1482

Pawson MG (1995) Biogeographical identification of English Channel fish and shellfish stocks. Fisheries Research Technical Report 99. Ministry of Agriculture, Fisheries and Food, Directorate of Fisheries Research, Lowestoft 
Plagányi ÉE, Butterworth DS (2004) A critical look at the potential of Ecopath with Ecosim to assist in pratical fisheries management. Afr J Mar Sci 26:261-287

Planque B, Fredou T (1999) Temperature and the recruitment of Atlantic cod (Gadus morhua). Can J Fish Aquat Sci 56: 2069-2077

Reid PC, Colebrook JM, Matthews JBL, Aiken J (2003) The Continuous Plankton Recorder: concepts and history, from plankton indicator to undulating recorders. Prog Oceanogr 58:117-173

Richardson AJ, Schoeman DS (2004) Climate impact on plankton ecosystems in the Northeast Atlantic. Science 305:1609-1612

Rijnsdorp AD, Vanbeek FA, Flatman S, Millner RM, Riley JD, Giret M, Declerck R (1992) Recruitment of sole stocks, Solea solea (L), in the Northeast Atlantic. Neth J Sea Res 29:U402-U402

Shannon, LJ, Christensen V, Walters CJ (2004) Modelling stock dynamics in the southern Benguela ecosystem for the period 1978-2002. Afr J Mar Sci 26:179-196

Southward AJ, Boalch GT, Maddock L (1988) Fluctuations in the herring and pilchard fisheries of Devon and Cornwall linked to change in climate since the 16th century. J Mar Biol Assoc UK 68:423-445

Southward AJ, Hawkins SJ, Burrows MT (1995) Seventy years' observations of changes in distribution and abun-

Editorial responsibility: Otto Kinne (Editor-in-Chief), Oldendorf/Luhe, Germany dance of zooplankton and intertidal organisms in the western English Channel in relation to rising sea temperature. J Therm Biol 20:127-155

Southward AJ, Langmead O, Hardman-Mountford NJ, Aiken J, Boalch GT and 14 others (2005) Long-term oceanographic and ecological research in the western English Channel. Adv Mar Biol 47:1-105

Stanford RJ, Pitcher TJ (2004) Ecosystem simulations of the English Channel: climate and trade-offs. Fisheries Centre Research Reports 12(3). The University of British Columbia, Vancouver

Ulrich C (2000) Modelisation multiflotilles et multi-metiers des percheries artisanales dela Manche. PhD thesis, l'Ecol Nationale Superieure Agronomigue de Rennes, Rennes

Ulrich C, Le Gallic B, Dunn MR, Gascuel D (2002) A multispecies multi-fleet bioeconomic simulation model for the English Channel artisanal fisheries. Fish Res 58:379-401

Walters C, Martell S (2004) Fisheries ecology and management. Princeton University Press, Princeton, NJ

Walters C, Pauly D, Christensen V, Kitchell JF (2000) Representing density dependent consequences of life history strategies in aquatic ecosystems: EcoSim II. Ecosystems 3: $70-83$

Ware DM, Thomson RE (2005) Bottom-up ecosystem trophic dynamics determine fish production in the Northeast Pacific. Science 308:1280-1284

Submitted: June 22, 2005; Accepted: September 1, 2005 Proofs received from author(s): January 25, 2006 